\title{
The Role of Climate Finance Beyond Renewables: Demand-Side Management (DSM) and Carbon Capture, Usage and Storage (CCUS)
}

\author{
Author Details \\ Dr. Peter Warren \\ School of Public Policy, University College London, 30 Tavistock Square, London, WC1H \\ 9QU, UK \\ E: peter.warren@ucl.ac.uk
}

\begin{abstract}
Mobilising climate finance for climate change mitigation is a crucial part of meeting the 'wellbelow' $2^{\circ} \mathrm{C}$ goal of the Paris Agreement. Climate finance refers to investments specifically in climate change mitigation and adaptation activities, which involve public finance and the leveraging of private finance. A large proportion of climate finance is Official Development Assistance (ODA) from OECD countries to ODA-eligible countries. The evidence shows that the largest proportion of climate finance for climate change mitigation has been channelled to the development of renewable energy, with a much smaller proportion flowing to other crucial forms of clean energy-related measures, such as demand-side management (DSM) (particularly sustainable cooling) and carbon capture, usage and storage (CCUS). This forms the rationale and aim of this synthesis paper: to review the role of climate finance to develop clean energy beyond renewables. In doing so, the paper draws on practical policy and programme experiences of some donor countries, such as the UK, and Development Finance Institutions (DFIs). This paper argues that a greater amount of climate finance from OECD countries to ODA-eligible fossil fuel-intensive emerging economies and developing countries is required for sustainable cooling and CCUS, particularly in the form of technical assistance and clean energy innovation.
\end{abstract}

\section{Key Policy Insights}

- Demand-side management (DSM) and carbon capture, usage and storage (CCUS) are underfunded in climate finance compared with the promotion of renewables.

- Climate finance for sustainable cooling, in particular, represents just $0.04 \%$ of total ODA, despite cooling projected to represent $13 \%$ of global emissions by 2030.

- Public investment in CCUS is limited at US \$28 billion since 2007, despite the costs of meeting the Paris Agreement estimated to be $40-128 \%$ more expensive without CCUS.

- Additional climate finance for these sectors should not come at the expense of funding for renewables but should be complementary to it.

\section{Key Words}

climate finance; green finance; demand-side management (DSM); sustainable cooling; carbon capture, usage and storage (CCUS); technical assistance; innovation

\section{Introduction}

A key part of the Paris Agreement (2015) is to make "finance flows consistent with a pathway towards low greenhouse gas emissions and climate-resilient development" (Article 2.1(c), UNFCCC, 2015). This includes a commitment to achieve at least US 
$\$ 100$ billion per year of climate finance flows from developed countries to developing countries by 2020 for climate change mitigation and adaptation activities (UNFCCC, 2015). Another important part of the Paris Agreement is the commitment for developed countries to provide capacity building support to developing countries for climate change mitigation and adaptation activities (discussed further in section two).

A large proportion of climate finance is Official Development Assistance (ODA) from OECD (Organisation for Economic Cooperation and Development) countries to ODAeligible non-OECD countries (listed on the Development Assistance Committee (DAC)'s List of ODA Recipients). The evidence shows that the largest proportion of climate finance that has focused on climate change mitigation activities has been channelled to the development of renewable energy, with a much smaller proportion flowing to other clean energy-related measures, such as demand-side management (DSM) (e.g. energy efficiency and flexibility), carbon capture, usage and storage (CCUS) or clean energy innovation (e.g. reducing emissions from sustainable cooling technological innovations). This forms the rationale and aim of the paper: to review the role of climate finance to develop clean energy beyond renewables. The paper aims to answer the following review questions:

a) What are the contested definitions within the climate finance field and what new definitions could resolve this?

b) What is the current status of climate finance globally and where are the funding gaps?

c) How important is climate finance beyond renewables, such as for DSM (in particular sustainable cooling) and CCUS?

Section two outlines the methodological approach to answer each of the review questions; section three examines the contested definitions in the climate finance field; section four reviews the current status of climate finance globally; section five discusses the importance of clean energy options beyond renewables, and section six provides the paper's overall conclusions.

\section{Review Methodology}

This section summarises and justifies the methodological approach of the review. The paper adopts Saunders et al.'s (2007) Research Process Onion theoretical framework to structure the research design, as it provides an effective way to visualise and categorise the scientific path from research philosophy to specific methods. Although it is perhaps too categorical and excludes certain research 'strategies' (such as modelling), or combined approaches (such as panel data analyses that combine cross-sectional and longitudinal data), the conceptual framework is nonetheless useful. The research design is visualised in figure one.

In the outermost sixth layer, this study fits into the pragmatism research philosophy, which focuses on using methods that are well suited to meeting the research aims (Morgan, 2007; Warren, 2015). This is in contrast to philosophical paradigms that give less freedom in the methods and tools that could be employed and instead focus on the approaches and strategies that should be employed, as can be the case with positivism and interpretivism (Saunders et al., 2007; Warren, 2015). In the fifth layer, the 'approach' employed is inductive, as data are synthesised and theories are built from the 
data rather than tested through hypotheses (Kellstedt and Whitten, 2013; Warren, 2015). However, as the review questions are more exploratory in nature, the inductive approach is more suitable for this research.

In the fourth layer, Saunders et al. (2007) identify seven main research 'strategies': experiments, surveys, case studies, action research, grounded theory, ethnography and archival research. For answering the three review questions, this study best fits the category of archival research (in its broadest sense), as it primarily uses documents as the sample for review and synthesis. In the third layer, this paper utilises a 'monomethod' approach (evidence reviews) and in the second layer, the research is 'crosssectional' rather than 'longitudinal', as the nature of the review questions warrant a more spatial-focused review (such as drawing on insights from case studies, in this case, from the UK).

In the innermost first layer, the research 'techniques and procedures' refer to the specific methods for data collection and data analysis. This research employs three review techniques: a non-systematic scoping review to answer the first two review questions and two systematic scoping reviews to answer the third review question (one for DSM and one for CCUS). Evidence reviews are defined as the use of systematic techniques to exhaustively collate and synthesise all of the evidence that has been produced on a particular intervention or programme to better understand what works and what does not (Petticrew and Roberts, 2006; Warren, 2018a; 2014a). Evidence reviews are a crucial method not only for collating and synthesising the evidence base, but also for determining the quality of previous evidence and extracting the most amount of value from previous studies using systematic techniques (Warren, 2014a). The method is commonly confused with literature reviews. However, Warren (2018a) clarifies that: "the former is a method for collecting data for analysis, whereas the latter is not a method, but instead aims to critique the current literature and to identify research gaps".

Systematic scoping reviews are a type of evidence review that are narrower in scope than systematic reviews, but are resource-efficient in their ability to be conducted quickly whilst remaining comprehensive and robust (Warren, 2018a). The two thematic evidence reviews (for DSM and CCUS) were undertaken following an evidence review protocol that applied systematic review techniques. Table one summarises the search strategy (sources and search terms), the inclusion criteria and the quality assessment scale adopted for each evidence review, and figure two shows the filtering process for producing the final sample for each theme (including the percentage change in the number of documents at key stages of the filtering process).

Quality assessment scales are an important part of evidence reviews, as they ensure that each relevant document in the final sample is of a high enough quality to be used in the synthesis (Warren, 2018a). This research adopted a scale that has been used in a number of energy and climate research projects commissioned by the UK Department for Business, Energy \& Industrial Strategy (BEIS), such as BEIS (2017a; 2017b; 2016a; 2016b). Table one presents the evidence quality assessment scale and as per BEIS (2017a; 2017b; 2016a; 2016b), documents must score at least two-thirds of the total number of points to be included in the review (6/9 points). Further information and background on evidence reviews in energy and climate policy can be found in Warren (2018a). As figure two shows, for DSM (sustainable cooling), 32.2\% (28 documents) of 
the initial sample (87 documents) met the inclusion criteria and were considered relevant to the synthesis and were of sufficient quality (at least 6/9 points on the scale) to be included in the final sample. For CCUS, 9.3\% (48 documents) of the initial sample (516 documents) was included in the final sample.

\section{Contested Definitions}

This section aims to review key contested definitions and terminology in the climate finance field, in order to bring them together under proposed common definitions. In particular, the section focuses on varying definitions for: 'climate finance', 'green finance', 'technical assistance', 'capacity building' and 'transformational change', and as such, these terms will be the focus of this section.

Environmentally-focused financial flows have emerged as a growing area for financial institutions and other investors. Part of this is driven by the growing push from shareholders, governments and customers for more ethical investments and greater transparency in the reporting of corporate investments. This moves historic business engagement in sustainability issues from environmental compliance and corporate environmental disclosure to minimal additional activities, such as corporate social responsibility or corporate environmental management, where activities are an 'add-on' to core business functions, to 'business sustainability', where ethical investments are a central part of core business functions. Concepts that are commonly associated with the latter include the Triple Bottom Line (TBL - people (social), planet (environmental) and profit (economic)) (Elkington, 1998), Creating Shared Value (CSV - generating economic value in a way that also produces societal value by addressing its challenges) (Porter and Kramer, 2011) and Responsible Investment (the selection, retention and rejection process for investments is based on conventional financial decision-making criteria along with moral considerations and Environmental, Social and Governance (ESG) criteria) (Herringer et al., 2009; Syed, 2017).

The terms 'green finance' and 'climate finance' have been used interchangeably in both the practitioner ('grey') literature and the academic literature, though some authors have tried to distinguish between them (for example, Lindenberg (2014); Höhne et al. (2012); Zadek and Flynn (2013); PwC (2013); Böhnke et al. (forthcoming)). Overall, it is clear that there are three key aspects that distinguish them. Firstly, green finance is the umbrella term that covers all forms of environmental management, from enhancing environmental goods and services to protecting against environmental damages. Secondly, climate finance is a sub-set of green finance and focuses specifically on climate change mitigation and adaptation. Thirdly, green finance includes all forms of financial investors, such as private finance, public finance and other forms of finance, but with a greater focus on private finance. In contrast, climate finance primarily focuses on public finance and the leveraging of private finance. The review finds that climate finance is usually used to invest in riskier projects or technical assistance activities (defined below) where there is usually limited interest from private sector investors due to the uncertain or unclear revenue streams (particularly in the case of technical assistance activities). As a result, governments often provide climate finance in the form of grants for technical assistance activities or concessional loans for riskier projects (where interest rates are below those available on the market or through the use of long grace periods (OECD, 2003)). 
The academic literature on the topic is limited and this paper aims to contribute to filling this gap. Much of the previous research on climate finance and green finance is found in the practitioner 'grey' literature, with institutions such as Development Finance Institutions (DFIs) (such as the World Bank Group) and Non-Governmental Organizations (NGOs) dominating the previous research on the topic. To contribute to filling this gap, this paper proposes the following definitions of green finance and climate finance:

"Green finance refers to investments (including preparatory, capital and operational costs) that enhance and protect environmental goods and services (including biodiversity, pollution control and climate change activities), or mitigate and adapt to environmental damages, which involve private finance, public finance and other forms of finance."

"Climate finance is a sub-set of green finance and refers to investments specifically in climate change mitigation and adaptation activities, which primarily involve public finance and the leveraging of private finance."

This paper focuses on the role of climate finance, rather than green finance, in climate change mitigation and the above definition is adopted. Figure three visualises the differences between the definitions in diagrammatic form.

Two further terms where definitions are contested and used interchangeably are 'technical assistance' and 'capacity building'. As with the definitions of 'green finance' and 'climate finance', much of the previous research on technical assistance and capacity building is found in the practitioner 'grey' literature (such as DFIs, NGOs and other development organizations) rather than the academic literature. To contribute to filling this gap, this paper proposes the following definitions of technical assistance and capacity building in the context of climate policy:

"Technical assistance refers to activities that facilitate capacity building, policy development, knowledge-sharing and project preparation to enable the deployment of technologies, actions and programmes to mitigate or adapt to climate change."

"Capacity building refers to targeted activities that develop the technical and institutional knowledge and skills necessary to enable the deployment of technologies, actions and programmes to mitigate or adapt to climate change".

The four definitions are based on the relevant documents in the evidence review, primarily from DFIs and international organisations (for example, ADB, 2010; Caruso and Ellis, 2013 (OECD); Climate Technology Centre and Network (CTCN), 2019; UNFCCC, 2019; World Bank, 2018), key academic sources (for example, Markandya et al., 2017; Haites, 2015) (see the bibliography for the full list) and the practical experiences of the UK Government's International Climate Fund (ICF) (for example, UK Government, 2018a; 2018b, which is discussed further in section five). Figure four visualises the differences between the definitions in diagrammatic form.

Technical assistance is the overarching term for non-capital projects and can be broken down into three main categories: capacity building, policy and advisory, and project preparatory. Capacity building technical assistance is focused on providing finance for 
enhancing clean energy knowledge and skills within supported countries, including facilitating (international) experts to undertake training for key stakeholders and organising dissemination events to share knowledge and experiences. Policy and advisory technical assistance refers to the provision of expert advice to support the development of the policy, and regulatory or legislative frameworks required to enable the development and deployment of clean energy technologies. Project preparatory technical assistance supports specific clean energy projects by funding (or part-funding) project proposals, feasibility studies, environmental, social, governance, economic and financial assessments, and monitoring and evaluation activities. The viability of capital projects is increased if grant-based technical assistance activities are linked to wider loans to support the financing of the capital projects that they are supporting, or where capital projects have a grant-based component. This is a common approach used by DFIs such as the ADB (e.g. ADB, 2018).

The use of climate finance to support clean energy innovation is less common than support for technical assistance or capital projects. However, technological, institutional and process (TP\&I) innovation (through research, development and demonstration (RD\&D)) can have an important impact on the development of bankable clean energy capital projects if combined with technical assistance activities.

Linked to the discussions on technical assistance is how 'transformational change' is defined. Climate finance has an important role in scaling up technical assistance activities and can be effective in achieving transformational change when targeted at specific clean energy technologies beyond renewables, such as CCUS, DSM and promising clean energy innovation technologies in developing countries. Where RD\&D focuses on the pre-deployment stages of new technologies (low Technology Readiness Levels (TRLs), transformational change primarily concentrates on the deployment stage where developing countries can deploy and replicate the previously supported technologies at scale. This paper defines transformational change as follows:

"Transformational change refers to the facilitation and realisation of the enabling contextual conditions to allow clean energy technologies to be sustainably deployed and replicated at scale".

Table two provides examples of the key enabling contextual conditions. The degree of transformational change is dependent on the number of key enabling contextual conditions that are developed. This definition is adapted from the theory of change for transformational change for the UK's ICF (e.g. see UK Government, 2018a; 2018b), as well as the academic literature, such as Warren (2017)'s Policy Transferability Framework.

Transformational change focuses on the achievement of longer-term outcomes and impacts and as such, it is a challenging concept for donor governments and DFIs to monitor and to evaluate. This is an area of current applied research in the literature (for example, see: Olsen et al., 2016; Olsen et al., 2015). As climate finance focuses on climate change mitigation and adaptation, some studies, such as Winkler and Dubash (2016), argue that there is a potential tension between climate finance and the wider sustainable development objectives of developing countries, which are defined through a national process. As such, in addition to important contextual factors, such as a stable and supportive political and policy environment, private sector support, innovation and 
local ownership (table two), an overarching clear link between climate finance and the sustainable development goals (SDGs), such as reducing poverty, improving health, improving education, fostering industry and infrastructure for economic growth, and reducing inequality (such as achieving gender quality) is essential if climate finance is to lead to transformational change in clean energy. This is particularly important for promising new, innovative clean energy technologies beyond established renewable energy technologies, such as hydro power, solar photovoltaics and onshore wind (discussed further in section five).

\section{Global Status of Climate Finance}

This section reviews the current status of climate finance globally and progress against the US $\$ 100$ billion per year by 2020 goal. The notion of the $2^{\circ} \mathrm{C}$ goal and the US $\$ 100$ billion per year by 2020 climate finance goal were introduced at COP 15 in 2009 as part of the Copenhagen Accords. In 2010, at COP 16, the Green Climate Fund (GCF) and the Adaptation Fund were established as part of the Cancun Agreements. The GCF forms an important part of the UNFCCC's financial mechanism for meeting the $2^{\circ} \mathrm{C}$ goal and by 2014, it had US $\$ 10.3$ billion of finance (GCF, 2019). However, under the Trump Administration, the USA announced that it would reduce its US $\$ 3$ billion commitment to the GCF by US $\$ 2$ billion (Bowman and Minas, 2019). Despite this, the GCF is going through replenishment discussions in 2019-2020. At COP 24, in 2018, Germany and Norway announced that they would double their contributions to the GCF.

The GCF supports both climate change mitigation and adaptation, whereas the Adaptation Fund focuses specifically on supporting the poorest and most vulnerable countries and communities to adapt to climate change. Since 2010, the Adaptation Fund has committed US $\$ 532$ million to around 80 climate adaptation and resilience projects (Adaptation Fund, 2019). At COP 24, just under US \$129 million of commitments to the Adaptation Fund were announced, which equates to its highest rate of finance mobilisation for a single year.

Quantifying progress against the US $\$ 100$ billion per year by 2020 goal is challenging due to issues in data collection and methodological aggregation in determining what counts as climate finance towards the target. Furthermore, data collection tends to be based on publicly declared or published figures on a country-by-country basis, with some countries being more transparent than others. Additionally, despite the political prominence of the GCF and the Adaptation Fund, there are a large number of climate funds of varying sizes globally, which makes the identification and aggregation of climate finance flows challenging. For example, the Climate Investment Funds (CIFs) were established in 2008 in support of the Bali Action Plan (which came out of COP 13 ). US $\$ 8.13$ billion of funds have been committed by 14 donor countries, which is held in two Trust Funds: the Clean Technology Fund (CTF) and the Strategic Climate Fund (SCF) (CIF, 2019). In contrast, there are a large number of smaller multilateral and single donor climate funds with capital of $<$ US \$200 million, such as the Asian Development Bank's multilateral Clean Energy Financing Partnership Facility (CEFPF) (ADB, 2018).

The European Commission (2017) estimates that progress against the US \$100 billion per year goal was US \$67 billion per year in 2015 and US \$70-75 billion per year in 
2017. This is based on a public declaration at COP 23 in Bonn in November 2017, and the methodology behind the estimates was not provided. US $\$ 23.4$ billion of the estimate came from the EU (up from US \$20.4 billion in 2015) (European Commission, 2017). The OECD has similarly struggled to produce up-to-date robust assessments of the status of climate finance. For example, one of the latest update reports from the OECD on this topic is from 2018, which simply states that: "updated estimates towards the US $\$ 100$ billion commitment will be needed in the run-up to 2020" before re-stating an old assessment that US \$62 billion had been mobilised in 2014 (Lamhauge and Jachnik, 2018). The OECD highlights that methodologies to assess and estimate climate finance mobilisation vary widely and there is considerable risk of double-counting (Caruso and Ellis, 2013).

Some studies, such as Westphal et al. (2015) have modelled different scenarios for meeting the 2020 goal (with a transparent methodology), in order to identify what is required from public and private sources of climate finance. The study presents four scenarios, and the results show that developed country climate finance alone will not reach the goal (scenario one). If the leveraging of private finance is included, the goal will only be met under a projection of high growth (of developed country finance) and high leverage (of private finance) (scenario two). However, if climate finance from DFIs, such as Multilateral Development Banks (MDBs), is added to this projection, then the goal can be met under a projection of medium growth and medium leverage (of both private finance and MDB finance). GBRW Consulting (2017) argues that MDBs are forecast to represent US $\$ 30$ billion of the US $\$ 100$ billion goal. If climate-related ODA is added to this projection, then the goal can be met under a projection of low growth and low leverage (Westphal et al., 2017).

The current status of climate finance globally stems beyond the specific parameters and sources that officially contribute towards the US $\$ 100$ billion per year commitment to also include private finance and wider sources of finance. Buchner et al. (2017) estimate that total climate finance was US \$383 billion in 2016 (US \$242 billion from private actors and US \$141 billion from public actors). This is a similar level to 2014 (US \$388 billion) but down from the level in 2015 (US $\$ 437$ billion), which could be explained in part by the greater amount of climate investment announcements by private actors as a result of the 2015 Paris Agreement. Climate finance from public actors was relatively stable between 2012-2016 but climate finance from private actors increased from US \$241 billion in 2014 to US \$299 billion in 2015 (Buchner et al., 2017).

The vast majority of climate finance from developed countries is channelled through DFIs: the World Bank Group, the Asian Development Bank (ADB), the Inter-American Development Bank (IADB), the African Development Bank (AfDB), the European Bank for Reconstruction and Development (EBRD), the Asian Infrastructure Investment Bank (AIIB) and the New Development Bank (NDB). However, by capital, MDBs are much smaller than conventional financial institutions with even the largest DFI (the World Bank) having capital of less than US \$30 billion (in 2017). This compares with the largest bank, the Industrial and Commercial Bank of China (ICBC), which had capital of around US \$270 billion in 2017 (GBRW Consulting, 2017). Institutional investors, such as pension funds and insurance companies, represent another potential large source of capital, though their climate investments have been limited to date. Nevertheless, this highlights the importance of other financial 
institutions and private sector actors in increasing the amount of climate finance invested in developing countries, particularly higher-emitting emerging economies.

Despite the progress made on mobilising an increasing amount of climate finance globally, investment in fossil fuels remains high. In 2016, investment in upstream and downstream fossil fuels was US $\$ 825$ billion (compared with US $\$ 383$ billion of climate finance) (Buchner et al., 2017), and in 2017 investment in fossil fuel supply was US $\$ 790$ billion (IEA, 2018a). For example, total finance from governments for new coal projects was US \$38 billion between 2013-2016 with US \$28 billion in the pipeline (Chen and Schmidt, 2017). In contrast, total finance from governments for new renewable energy projects was US \$25 billion between 2013-2016 with US \$14 billion in the pipeline (Chen and Schmidt, 2017). Furthermore, although global investment in new coal-fired plants reduced in 2016 with $20 \mathrm{GW}$ less coal commissioned, $40 \mathrm{GW}$ of new coal-fired plants was still commissioned (IEA, 2018a). This highlights the importance of parallel climate policy that aims to increase the amount of climate finance whilst reducing the amount of finance for fossil fuels, in order to meet the 'well-below' $2^{\circ} \mathrm{C}$ goal of the Paris Agreement.

Piggot et al. (2018) argue that there is a strong rationale for countries to pursue a phasedown in fossil fuel production (not just consumption) as part of the Paris Agreement and the UNFCCC process. Similarly, Peake and Ekins (2017) highlight the important need to divert scheduled investments in the fossil-fuel industry towards renewables, energy efficiency, and other low or negative carbon technologies, in order to limit temperature increases to $2^{\circ} \mathrm{C}$. Alongside coal- and oil-based fuels, unabated natural gas is also included within the group of fossil fuels and decarbonising natural gas across the full gas chain (gas processing, gas production, industrial gas use and gas power) is an area of current joint research between the World Bank, the ADB and the IEA with funding from the UK's ICF. Broto (2016) argues that gas-related projects will rarely be eligible for climate finance, except in rare context-specific situations where they provide energy access directly to households. However, in such situations, climate finance is likely to fund technical assistance activities, such as detailed feasibility studies on how to decarbonise proposed gas-related projects, rather than supporting unabated gas projects themselves.

At COP 24, countries committed to start the process in 2020 of setting a new climate finance goal beyond the current target of US $\$ 100$ billion per year for the period after 2025 (WRI, 2018). Furthermore, countries agreed to undertake an assessment of the climate finance needs of developing countries every four years (WRI, 2018).

\section{Beyond Renewables}

This section aims to summarise the findings from the two evidence reviews undertaken for this paper that focused on underfunded areas of climate finance beyond renewables: DSM (particularly sustainable cooling) and CCUS. As the syntheses below show, both of these themes are crucial for support alongside renewables to meet the goals of the Paris Agreement.

As discussed in section 5.1, sustainable cooling can make an important contribution to meeting a whole range of SDGs from improving health and reducing hunger through reduced food loss (from improved cold chains) to building sustainable cities and 
communities. However, cooling is projected to represent $13 \%$ of global greenhouse gas emissions by 2030 (GIZ Proklima, 2018) and currently just $0.04 \%$ of total ODA has been committed to cooling (K-CEP, 2018). With the projected growth in demand for cooling, it is important not only to scale-up the amount of climate finance for cooling, but also to ensure that cooling is low carbon and does not exacerbate the climate problem. Climate finance will play an important role in this regard.

As discussed in section 5.2, CCUS is particularly important in addressing the hard-todecarbonise sectors, such as industry (particularly energy-intensive industries that cannot be electrified or use alternative lower carbon fuels) and transport (through clean hydrogen production or clean electricity production). Limited climate finance has been provided to CCUS to date, despite the growing evidence base highlighting its necessity for keeping global temperature increases to 'well-below' $2^{\circ} \mathrm{C}$ (IPCC, 2018; 2014, and IEA, 2016).

The review also identified other themes that are important from a climate mitigation perspective but which are underfunded through climate finance, such as clean transport and greenhouse gas removal technologies like direct air capture. However, as this paper focuses primarily on the energy sector, further research should investigate these other underfunded themes.

\subsection{Demand-Side Management: Sustainable cooling}

DSM refers to demand-side actions and programmes that seek to manage energy consumption in order to meet various policy objectives, such as carbon emissions reduction and energy security (Warren, 2019; 2018b; 2014b) In 2017, total global investment in demand-side activities (beyond just climate finance) was US \$236 billion (IEA, 2018a). This compares with US \$300 billion for renewable power in 2017 (IEA, 2018a). The figure primarily refers to investments in energy efficiency in buildings, transport and industry rather than other forms of DSM, such as demand-side response, energy conservation, smart technologies, on-site energy storage or on-site (clean energy) generation. Public sources of climate finance for energy efficiency for climate change mitigation were US $\$ 39$ billion in 2015/2016, ahead of renewable energy generation (US $\$ 34$ billion) and sustainable transport (US \$22 billion) (Buchner et al., 2017).

From a thematic perspective, within DSM, it is clear that sustainable cooling has received limited attention in the climate finance space, despite the use of air conditioners and electric fans currently representing $20 \%$ of the total electricity consumption in buildings (and 10\% of all global electricity consumption and $14 \%$ of peak electricity demand), with $\mathrm{CO}_{2}$ emissions from cooling tripling since 1990 to 1.13 billion tonnes (IEA, 2018b). The IEA (2018b) estimates that there are 1.6 billion units currently around the world with a combined total electricity consumption of 2,000 $\mathrm{TWh} /$ year (over half of the existing units are in China and the USA). Furthermore, the average energy efficiency of air conditioners is less than half of what is available for consumers to buy (IEA, 2018b), highlighting that consumers are not buying the most energy efficient units.

The IEA's Efficient Cooling Scenario highlights that the efficiency of air conditioners can be doubled through effective minimum energy efficiency performance standards 
and consequently reducing energy demand from cooling by $45 \%$ by 2050 (IEA, 2018b). Coupled with the decarbonisation of the power sector, emissions from cooling would reduce to $150 \mathrm{mtCO}_{2}$ (13\% of the 2016 level) (IEA, 2018b). R\&D has an important role to play as well. However, global investment in energy R\&D was just US \$27 billion in 2017 with two-thirds of this channelled towards low carbon technology innovation (IEA, 2018b).

Of the 2.8 billion people living in the hottest parts of the world, only $8 \%$ currently possess air conditioners (SEforAll, 2018). SEforAll (2018) estimates that over 1.1 billion people face risks from a lack of access to cooling, which has important benefits in alleviating poverty, improving health (through keeping vaccines stable and food nutritious across the cold chain) and improving economic productivity. Increasing access to cooling without associated improvements in energy efficiency would lead to 2,800 TWh of additional electricity consumption than would otherwise be required by 2050 with energy efficient air conditioners (IEA, 2018b). Even with energy efficient air conditioners, total electricity consumption would still increase to 3,400 TWh by 2050 as access to cooling is improved (70\% higher than in 2016) (IEA, 2018b). Thus, in addition to efficient cooling, climate finance for RD\&D into sustainable cooling alternatives, such as natural refrigerants, utilising waste cooling ('coolth') from industrial (and other) processes for district cooling, heat pumps, fuel switching, etc. will also be required.

From a climate finance perspective, the Multilateral Fund under the 1987 Montreal Protocol represents one of the few sources of climate finance for cooling. The fund was established in 1991 and is specifically related to the Montreal Protocol and the phase down of ozone-depleting substances, such as chlorofluorocarbons (CFCs) and halons. To date the fund has committed US $\$ 3.6$ billion to activities, such as industrial conversion, training and capacity building (Multilateral Fund, 2019). In 2016, the Kigali Amendment to the Montreal Protocol was agreed, with the aim of achieving an $80 \%$ reduction in hydrofluorocarbons (HFCs) by 2047. It came into force in 2019. The Kigali Cooling Efficiency Program (K-CEP) was established as a philanthropic programme to support the Kigali Amendment; it estimates that just $0.04 \%$ of total ODA has been committed to sustainable cooling (K-CEP, 2018), thus highlighting a large climate finance gap.

Similarly, since its establishment in 1995, GIZ Proklima has been working on behalf of the German Federal Ministry for the Environment, Nature Conservation and Nuclear Safety (BMU) to disseminate ozone-friendly and climate-friendly cooling technologies through its Green Cooling Initiative (GIZ Proklima, 2018). For example, a project on refrigeration and air conditioning in Thailand is currently being funded through the NAMA Facility (Nationally Appropriate Mitigation Actions) from 2016-2021 (EUR 14.7 million of funding) (NAMA Facility, 2017). The multilateral NAMA Facility has donor funding from Germany, the UK, Denmark and the European Commission. Technical assistance is a strong component of the Thailand project, as well as a new project on cooling in Colombia funded also through the NAMA Facility. This highlights the importance of technical assistance alongside RD\&D funding to ensure that the development of sustainable cooling technologies is coupled with the development of the required technical and institutional knowledge, skills and capability (capacity building), and the establishment of the necessary regulatory, legislative or policy frameworks, to enable the deployment of those technologies. For example, providing technical 
assistance to developing countries to design and implement the appliance efficiency recommendations of the CLASP and SEAD (Super-efficient Equipment and Appliance Deployment) initiatives would be one possible first step for addressing cooling emissions in the buildings sector. These initiatives aim to provide governments and industry stakeholders with the key resources to enable the promotion and implementation of improved energy efficiency for appliances and equipment.

There are growing signs that cooling is moving up the climate finance agenda. For example, the UK Government's clean energy innovation programme, established in 2019 , represents one of the few new sources of climate finance that targets sustainable cooling innovation in developing countries (alongside two other themes: energy storage and industrial decarbonisation, including CCUS) with links to Mission Innovation. Mission Innovation is a global initiative of 23 countries and the European Commission working to accelerate global clean energy innovation with the objective of making clean energy widely affordable. Similarly, the World Bank is in the process of establishing a Sustainable Cooling Initiative to identify how to scale-up finance for sustainable cooling in developing countries.

The evidence review undertaken for this paper highlights the important need to increase the amount of climate finance provided for sustainable cooling to help developing countries to mitigate and adapt to climate change. IEA (2018b) describes cooling as "one of the most critical blind spots in today's energy debate". Cooling is projected to represent 13\% of global greenhouse gas emissions by 2030 (GIZ Proklima, 2018) with most of the growth coming from emerging economies and developing countries. Based on current projections, overall energy demand from the cooling sector will increase by $90 \%$ by 2050 (7,500-9,500 TWh) (Peters, 2018) without increased investment in innovation for sustainable cooling. As such, there is a crucial role for climate finance to stimulate investment and innovation in sustainable cooling in these countries. In particular, support for innovation (TP\&I) alongside support for technical assistance would contribute to developing the necessary enabling contextual conditions to achieve transformational change, as summarised in table two. For example, climate finance would help to reduce the barriers to private sector investment in sustainable cooling.

\subsection{Carbon Capture, Usage and Storage (CCUS)}

It is estimated that CCUS could capture around $90 \%$ of $\mathrm{CO}_{2}$ emissions from point sources, such as industrial processes or power plants, to prevent their release into the atmosphere (Markewitz et al., 2012; Cuéllar-Franca and Azapagic, 2015) and then to transfer them to a suitable site for long-term storage (Markewitz et al., 2012; IPCC, 2005) or to use the captured $\mathrm{CO}_{2}$ in commercial products (Styring et al., 2011; Markewitz et al., 2012). $\mathrm{CO}_{2}$ can be captured through post-combustion, pre-combustion or oxyfuel combustion (see Global CCS Institute (2018a) for further details).

Since 2007, just US \$28 billion has been earmarked for large-scale CCUS, of which just $15 \%$ was spent due to the challenges of leveraging private finance from public finance (IEA, 2018a). There are just 18 large-scale CCUS plants in operation and a further four under construction (Global CCS Institute, 2018b). This compares with total global investments of US $\$ 750$ billion for renewables and US \$236 billion for energy efficiency in 2017 alone, as stated previously (IEA, 2018a). Estimates of the market potential for CCUS range from a niche market (CSLF, 2013) to a US $\$ 800$ billion 
market (Global $\mathrm{CO}_{2}$ Initiative (GCI), 2016). However, the CCUS evidence review identifies that CCUS needs to make up $12-14 \%$ of carbon dioxide emissions reductions in the power sector alone to meet the Paris Agreement's "well below" $2^{\circ} \mathrm{C}$ target (IEA, 2016; IEA, 2013). The IPCC's special report on Global Warming of $1.5^{\circ} \mathrm{C}$ reemphasises the critical need for CCUS (IPCC, 2018). Furthermore, current estimates suggest that it will be considerably more expensive to meet the Paris Agreement targets without CCUS; well-cited estimates range from at least 40\% (IEA, 2016) to $138 \%$ (between 29-297\%) (IPCC, 2014) more. Despite the variation in the specific estimates due to the challenges of modelling how costs will change over time for different technologies, all estimates agree that costs are higher without CCUS.

Such evidence highlights that the applications of CCUS are particularly important in achieving deep decarbonisation in the fossil-fuel intensive industrial sectors, such as iron and steel, chemicals and petrochemicals, power and cement. IEA (2016) estimates that in the IEA's $2^{\circ} \mathrm{C}$ scenario, CCUS need to contribute up to $20 \%$ of the cumulative emissions reductions in industrial processes in the production of iron, steel and cement $\left(29 \mathrm{GtCO}_{2}\right)$ through 2050.

Furthermore, CCUS has important applications in providing a low carbon source for hydrogen production (such as to decarbonise space heating), a mechanism to allow back-up capacity for peak supply-demand balancing purposes in the absence of nonvariable renewable alternatives (such as hydro power or geothermal power), and in decarbonising the full gas chain, such as gas production, gas processing, industrial gas use and gas power.

Similarly, as an alternative to $\mathrm{CO}_{2}$ storage, evidence from on-the-ground experiences, such as those captured through the UK government's $£ 70$ million ODA international CCUS programme (discussed further below) show that captured $\mathrm{CO}_{2}$ can be utilised in a number of industries, such as in the production of methanol, urea and polymers, and in Enhanced Oil Recovery (EOR) and Enhanced Gas Recovery (EGR). This has been particularly important in developing the commercial business models for CCUS. However, further research is required to understand the lifecycle greenhouse gas emissions reductions of each of these options to ensure that overall emissions are reduced rather than (unintentionally) increased, which might be a risk in certain contexts for EOR and EGR in particular.

To date, limited climate finance has been provided for CCUS. The existing climate finance has primarily been provided through the UK government, the Australian government (through the Global CCS Institute) and the Norwegian government. The primary mechanism for the provision of climate finance for CCUS has been through MDBs, in particular the World Bank's CCUS Trust Fund (total of US \$61.2 million of climate finance) and the ADB's CCUS Fund (which comes under the ADB's wider Clean Energy Partnership Financing Facility) (total of US \$41.1 million of climate finance) (UK Government, 2018b). Some countries, such as Norway and Japan, have also provided climate finance bilaterally to specific countries (such as South Africa and Indonesia, respectively). The UK government's international CCUS programme is the largest provider of climate finance to CCUS ( $£ 70$ million), which is delivered through MDBs (UK Government, 2018b). However, as with sustainable cooling, this is dwarfed by the amount of climate finance that OECD countries are providing to renewables. 
International initiatives, such as Mission Innovation, the IEA's Greenhouse Gas Emissions Reductions programme (IEA GHG) and the Carbon Sequestration Leadership Forum (CSLF), highlight the important need for CCUS innovation and RD\&D to reduce the costs of $\mathrm{CO}_{2}$ capture, which is considered an important barrier to the deployment of CCUS (Mission Innovation, 2019; IEA GHG, 2018; CSLF, 2018). However, costs will vary based on local contexts, such as labour costs, energy costs, the particular technologies used and the specific applications (the type and size of the power plant or industrial facility) (ADB, 2015). $\mathrm{CO}_{2}$ utilisation may provide an important mechanism to reduce costs and improve the commercial case for $\mathrm{CO}_{2}$ capture, particularly from industrial plants.

Estimates of the costs of $\mathrm{CO}_{2}$ capture currently range from additional costs of $2 \%$ to $70 \%$ (Global CCS Institute, 2017). The costs vary due to differences in national and local contextual conditions and the sectors where CCUS is applied. For example, the ADB (2015) estimates additional costs of US $\$ 500$ million to power plant construction costs (for $\mathrm{CO}_{2}$ capture, transportation and storage), whereas in India, $\mathrm{CO}_{2}$ capture and usage from industrial plants has been demonstrated as costing just US $\$ 20-40 \mathrm{tCO}_{2}$, and these costs are trying to be replicated in other countries (Carbon Clean Solutions, 2018). In the UK, Element Energy et al. (2014) estimate that the costs of industrial retrofit of different $\mathrm{CO}_{2}$ capture technologies are EUR $€ 60 \mathrm{tCO}_{2}$ (iron and steel), EUR $€ 75 \mathrm{tCO}_{2}$ (cement), EUR $€ 65 \mathrm{tCO}_{2}$ (petroleum) and EUR $€ 10 \mathrm{tCO}_{2}$ (high purity sources). Pieri et al. (2018) and the Global CCS Institute (2017) provide comprehensive reviews of the costs of CCUS.

Alongside climate finance for innovation to reduce costs and improve the commercial model for CCUS, a further important barrier to the development of CCUS in fossil fuelintensive emerging economies and developing countries is limited technical and institutional knowledge, skills and capability. The role of climate finance to provide technical assistance for CCUS is thus crucial, as has been the experiences of donors such as the UK and Norway (UK Government, 2018b). Technical assistance activities include undertaking feasibility studies, piloting $\mathrm{CO}_{2}$ capture technologies, undertaking site characterisation and test injections for $\mathrm{CO}_{2}$ storage, supporting the establishment of regulatory, policy or legislative frameworks to enable CCUS, undertaking CCUS training events to build capacity, skills and knowledge, and supporting the establishment of the necessary incentive structures to support CCUS demonstration and ultimately accelerate the deployment of CCUS. The success of technical assistance activities in countries such as Mexico, South Africa, China and Indonesia that have been supported through the UK's international CCUS programme indicates that increased climate finance for such activities is necessary for achieving medium-term development benefits, such as climate change mitigation, health improvements through local air pollution reduction, economic benefits through new CCUS markets, job creation and exporting expertise and technologies, and local poverty reduction (UK Government, $2018 \mathrm{~b}$ ). Thus, the role of climate finance for technical assistance is to develop the enabling contextual conditions to achieve transformational change that are summarised in table two. Figure five is an example of a summary theory of change from the UK's international CCUS programme (the circled factors are those that are the focus of the monitoring and evaluation for the programme) (UK Government, 2018b).

The evidence review highlights the important need to increase the amount of climate finance provided for CCUS to help fossil fuel-intensive emerging economies and 
developing countries to mitigate the emissions from their growing industrial and power sectors. Due to the global nature of climate change, this should complement the introduction of policy incentives in advanced economies. For example, the USA's 45Q tax credit adjustments for CCUS is likely to increase CCUS development and investment. The policy increases the current level of tax credits from US $\$ 10 \mathrm{tCO}_{2}$ to US $\$ 35 \mathrm{tCO}_{2}$ by 2024 for $\mathrm{CO}_{2}$ utilisation (including EOR) and US $\$ 50 \mathrm{tCO}_{2}$ for geological (saline) storage. It was introduced in February 2018 as part of the Bipartisan Budget Act (providing the incentive for twelve years if construction begins before 2024) (USC 45Q, 2018). Similarly, the UK's CCUS Action Plan, published in November 2018, highlighted a suite of policies to enable the option to deploy CCUS in the UK in the 2030s.

Providing policy, regulatory and legislative technical assistance to ODA-eligible countries to learn from these experiences is thus an important enabling factor for achieving transformational change in these countries. Furthermore, there is a critical need for climate finance to develop increasingly important wider applications of CCUS, such as to achieve deep industrial decarbonisation, to decarbonise the gas chain, for peak demand balancing and to decarbonise hydrogen production, which are areas that renewables have struggled to address to date. As argued at the start of this section, climate finance beyond renewables should not be at the expense of funding for renewables but complementary to it, as the focus of these technologies is particularly relevant in addressing the hard-to-decarbonise sectors.

\section{Conclusions}

The paper aimed to review the role of climate finance in the development of clean energy-related measures beyond renewables by employing evidence reviews using systematic techniques to address three main areas: what the contested definitions are within the climate finance field, what the current status of climate finance is globally and where the funding gaps are, and how important climate finance is beyond renewables, in particular focusing on DSM (specifically sustainable cooling) and CCUS.

Definitions of climate finance, technical assistance, capacity building and transformational change are particularly contested in the literature with terms such as green finance and climate finance, or technical assistance and capacity building, incorrectly used interchangeably. The climate finance literature is dominated by the practitioner (grey) literature rather than the academic literature, and this paper aimed to contribute to filling this gap by synthesising, clarifying and proposing holistic definitions for each of these terms.

The current status of climate finance globally is mixed. Although US \$383 billion of climate finance was provided in 2016, investment in upstream and downstream fossil fuels was US $\$ 825$ billion. Similarly, although total global investment in DSM (beyond just climate finance) was US \$236 billion in 2017 and US \$300 billion for renewables, just US \$39 billion of climate finance was provided for DSM (specifically energy efficiency) in 2015/2016 and just US $\$ 34$ billion was provided for renewables.

However, within DSM, just $0.04 \%$ of ODA has been provided for sustainable cooling to date, despite overall energy demand from the cooling sector projected to increase by 
$90 \%$ by $2050(7,500-9,500 \mathrm{TWh})$ and to represent 13\% of global emissions by 2030 . Similarly, just US \$28 billion has been invested in CCUS since 2007 (beyond just climate finance), despite the evidence highlighting that it needs to make up $12-14 \%$ of decarbonisation efforts by 2050 , otherwise it would be at least $40 \%$ more expensive to meet the 'well-below' $2{ }^{\circ} \mathrm{C}$ goal of the Paris Agreement without CCUS. This is primarily due to its important applications in decarbonising industrial sectors, the gas chain, peak demand balancing and hydrogen production.

Overall, the review highlights that there is a crucial role for climate finance beyond renewables, particularly for sustainable cooling (across the cold chain) and CCUS in emerging economies and developing countries. This paper argues that climate finance needs to target technical assistance and innovation, in order to enable the contextual conditions that would allow less-supported clean energy options to be sustainably deployed and replicated at scale.

\section{Declaration of Interest Statement}

There are no potential conflicts of interest with respect to the research, authorship and/or publication of this article.

\section{Bibliography}

1. Adaptation Fund (2019) "About", can be accessed from: https://www.adaptationfund.org/about/ [accessed on 16/02/2019]

2. Asian Development Bank (ADB) (2010) Technical Assistance Disbursement Handbook, ADB, May 2010, can be accessed from: https:/www.adb.org/sites/default/files/institutionaldocument/31314/tadisbursement.pdf [accessed on 04/11/2018]

3. Asian Development Bank (ADB) (2015) Roadmap for carbon capture and storage demonstration and deployment in the people's Republic of China, ADB, November 2015, can be accessed from: https://www.adb.org/sites/default/files/publication/175347/roadmapccs-prc.pdf [accessed on 10/11/2018]

4. Asian Development Bank (ADB) (2018) Clean Energy Financing Partnership Facility Annual Report 2017, ADB, July 2018, can be accessed from: https://www.adb.org/sites/default/files/institutional-document/437331/cefpf-annual-report2017.pdf [accessed on 04/11/2018]

5. Böhnke, Eidt, Knierim, Richert, Röber and Volz (unpublished) "How to make green finance work - empirical evidence from bank and company surveys", German Development Institute, can be accessed from: https://www.die-gdi.de/en/green-finance/ [accessed on $04 / 11 / 2018]$

6. Bowman, M. and Minas, S. (2019) "Resilience through interlinkage: the green climate fund and climate finance governance", Climate Policy, 19 (3), pp. 342-353

7. Buchner, B.; Oliver, P.; Wang, X.; Carswell, C.; Meattle, C. and Mazza, F. (2017) Global Landscape of Climate Finance 2017, Climate Policy Initiative (CPI), October 2017, can be accessed from: https://climatepolicyinitiative.org/publication/global-landscape-of-climatefinance-2017/ [accessed on 04/11/2018]

8. Carbon Clean Solutions (2018) "Innovating to reduce the cost of carbon capture", can be accessed from: http://www.carboncleansolutions.com/home [accessed on 10/11/2018]

9. Carbon Sequestration Leadership Forum (CSLF) (2013) "Phase 2 final report by the CSLF Task Force on $\mathrm{CO}_{2}$ Utilization Options", Technical Group, CSLF, can be accessed from: https://www.cslforum.org/cslf/sites/default/files/documents/CO2UtilizationOptions Phase2 FinalReport.pdf [accessed on 10/11/2018]

10. Carbon Sequestration Leadership Forum (CSLF) (2018) Carbon Sequestration Leadership Forum, can be accessed from: https://www.cslforum.org/cslf/ [accessed on 04/11/2018] 
11. Caruso, R. and Ellis, J. (2013) "Comparing Definitions and Methods to Estimate Mobilised Climate Finance", OECD/IEA Climate Change Expert Group Papers, No. 2013/02, OECD Publishing, Paris, France, can be accessed from: https://doi.org/10.1787/5k44wj0s6fq2-en [accessed on 16/02/2019]

12. Chen, H. and Schmidt, J. (2017) "Power shift: shifting G20 international public finance from coal to renewables", Natural Resources Defense Council (NRDC), December 2017, can be accessed from: https://www.nrdc.org/sites/default/files/power-shift-g20international-public-finance-coal-renewables-report.pdf [accessed on 04/11/2018]

13. CLASP (2019) "Who we are", can be accessed from: https://clasp.ngo [accessed on $16 / 02 / 2019]$

14. Climate Investment Funds (CIFs) (2019) "Governance", can be accessed from: https://www.climateinvestmentfunds.org/governance [accessed on 16/02/2019]

15. Cuéllar-Franca, R.M. and Azapagic, A. (2015) "Carbon capture, storage and utilisation technologies: A critical analysis and comparison of their life cycle environmental impacts", Journal of $\mathrm{CO}_{2}$ Utilization, 9, pp. 82-102

16. Department for Business, Energy and Industrial Strategy (BEIS) (2016a) Occupancy patterns scoping review project, London: HMSO, can be accessed from: www.gov.uk/government/uploads/system/uploads/attachment_data/file/565281/Final_Repo rt - Occupancy Patterns Scoping Review Project.pdf [accessed on 04/11/2018]

17. Department for Business, Energy and Industrial Strategy (BEIS) (2016b) Scoping review of heating controls project, London: HMSO, can be accessed from: www.gov.uk/government/uploads/system/uploads/attachment data/file/573888/Final_Repo rt - Heating Controls Scoping_Review Project.pdf [accessed on 04/11/2018]

18. Department for Business, Energy and Industrial Strategy (BEIS) (2017a) Heating controls: International evidence base and policy experiences, London: HMSO, can be accessed from: www.gov.uk/government/policies/household-energy [accessed on 04/11/2018]

19. Department for Business, Energy and Industrial Strategy (BEIS) (2017b) Realising the potential of demand-side response to 2025, London: HMSO, www.gov.uk/government/policies/household-energy [accessed on 04/11/2018]

20. Element Energy, Carbon Counts, PSE, Imperial College London and the University of Sheffield (2014) "Demonstrating $\mathrm{CO}_{2}$ Capture in the UK Cement, Chemicals, Iron and Steel and Oil Refining Sectors by 2025: A Techno-Economic Study", Final report for the UK Department of Energy and Climate Change (DECC) and the UK Department for Business, Innovation and Skills (BIS), April 2014, Element Energy, Cambridge, UK, can be accessed from: http://www.element-energy.co.uk/wordpress/wpcontent/uploads/2017/06/Element Energy DECC BIS Industrial_CCS and CCU final re port 14052014.pdf [accessed on 10/11/2018]

21. Elkington, J. (1998) Cannibals with Forks: The Triple Bottom Line of 21st Century Business, New Society Publishers

22. European Commission (2017) "EU expects solid progress on Paris Agreement implementation at UN climate conference in Bonn", Press release, European Commission, $6^{\text {th }}$ November 2017, Brussels, Belgium, can be accessed from: http://europa.eu/rapid/pressrelease IP-17-4245 en.htm [accessed on 10/11/2018]

23. GBRW Consulting (2017) Multilateral development banks: banking and financial policy issues, GBRW, can be accessed from: http://www.gbrw.com/gbrw consulting projects [accessed on 04/11/2018]

24. GIZ Proklima (2018) "Green Cooling Initiative", can be accessed from: https://www.greencooling-initiative.org [accessed on 10/11/2018]

25. Global CCS Institute (2017) "Global Costs of Carbon Capture and Storage: 2017 Update", Global CCS Institute, June 2017, can be accessed from: http:/hub.globalccsinstitute.com/sites/default/files/publications/201688/global-ccs-costupdatev4.pdf [accessed on 10/11/2018]

26. Global CCS Institute (2018a) "Capture", Global CCS Institute, can be accessed from: https://www.globalccsinstitute.com/understanding-ccs/how-ccs-works-capture [accessed on 10/11/2018] 
27. Global CCS Institute (2018b) "The Global Status of CCS: 2018", Global CCS Institute, can be accessed from: https://www.globalccsinstitute.com [accessed on 10/11/2018]

28. Global $\mathrm{CO}_{2}$ Initiative (GCI) (2016) "Carbon dioxide utilization $\left(\mathrm{CO}_{2} \mathrm{U}\right)$ - ICEF roadmap 1.0", GCI and ICEF (Innovation for Cool Earth Forum), can be accessed from: https://www.icef-forum.org/pdf2018/roadmap/CO2U Roadmap ICEF2016.pdf [accessed on $10 / 11 / 2018]$

29. Green Climate Fund (GCF) "About the fund", can be accessed from: https://www.greenclimate.fund/who-we-are/about-the-fund [accessed on 16/02/2019]

30. Haites, E. (2015) International climate finance, Routledge

31. Herringer, A.; Firer, C. and Viviers, S. (2009) "Key challenges facing the socially responsible investment (SRI) sector in South Africa", Investment Analysts Journal, 38 (70)

32. Höhne, Khosla, Fekete and Gilbert (2012) "Mapping of green finance delivered by IDFC members in 2011", Ecofys

33. Intergovernmental Panel on Climate Change (IPCC) (2005) IPCC Special Report on Carbon Dioxide Capture and Storage, Cambridge University Press, can be accessed from: https://www.ipcc.ch/pdf/special-reports/srccs/srccs wholereport.pdf [accessed on $10 / 11 / 2018]$

34. Intergovernmental Panel on Climate Change (IPCC) (2014) Climate Change 2014: Synthesis Report, IPCC, can be accessed from: http://ar5syr.ipcc.ch/ipcc/ipcc/resources/pdf/IPCC SynthesisReport.pdf [accessed on 10/11/2018]

35. Intergovernmental Panel on Climate Change (IPCC) (2018) Special Report on Global Warming of $1.5^{\circ} \mathrm{C}$, IPCC

36. International Energy Agency (IEA) (2013) "Global Action to Advance Carbon Capture and Storage: A Focus on Industrial Applications", Annex to Tracking Clean Energy Progress 2013, IEA: OECD, Paris, France

37. International Energy Agency (IEA) (2016) 20 Years of Carbon Capture and Storage: Accelerating Future Deployment, IEA: OECD, Paris, France

38. International Energy Agency (IEA) (2018a) World Energy Investment Outlook 2018, Organisation for Economic Co-operation and Development (OECD), can be accessed from: https://www.iea.org/wei2018/ [accessed on 04/11/2018]

39. International Energy Agency (IEA) (2018b) The Future of Cooling, Organisation for Economic Co-operation and Development (OECD), can be accessed from: https://www.iea.org/cooling/ [accessed on 04/11/2018]

40. International Energy Agency Greenhouse Gas Emissions Reduction Programme (IEA GHG) (2018) IEA GHG R\&D Programme, can be accessed from: https://ieaghg.org [accessed on 04/11/2018]

41. Kellstedt, P.M. and Whitten, G.D. (2013) The Fundamentals of Political Science Research, $2^{\text {nd }}$ edition, New York: Cambridge University Press

42. Kigali Cooling Efficiency Program (K-CEP) (2018) "Why cooling", can be accessed from: https://www.k-cep.org/why-cooling/ [accessed on 10/11/2018]

43. Lamhauge, N. and Jachnik, R. (2018) "Tracking climate finance: Progress and challenges", Organisation for Economic Co-operation and Development (OECD), can be accessed from: https://doi.org/10.1787/f685d437-en [accessed on 16/02/2019]

44. Lindenberg, N. (2014) "Definition of green finance", German Development Institute, can be accessed from: https://www.cbd.int/financial/gcf/definition-greenfinance.pdf [accessed on 04/11/2018]

45. Markandya, A., Galarraga, I. and Rubbelke, D. (2017) Climate finance theory and practice, Volume 2, World Scientific Series on the Economics of Climate Change: Singapore

46. Markewitz, P., Kuckshinrichs, W., Leitner, W., Linssen, J., Zapp, P., Bongartz, R., Schreiber, A., Müller, T.E. (2012) "Worldwide innovations in the development of carbon capture technologies and the utilization of $\mathrm{CO}_{2}$ ", Energy and Environmental Science, 5 (6), pp. $7281-7305$

47. Mission Innovation (2019) "Carbon capture challenge" http://mission-innovation.net/ourwork/innovation-challenges/carbon-capture-challenge/ [accessed on 16/02/2019] 
48. Morgan, D.L. (2007) "Paradigms lost and pragmatism regained: methodological implications of combining qualitative and quantitative methods", Journal of Mixed Methods Research, 1 (1), pp. 48-76

49. Multilateral Fund (2019): "Home", can be accessed from: http://www.multilateralfund.org/default.aspx [accessed on 16/02/2019]

50. NAMA Facility (2017) "Thailand Refrigeration and Air Conditioning NAMA", can be accessed from: http://www.namadatabase.org/index.php/Thailand_Refrigeration_and_Air_Conditioning_NAMA [accessed on $10 / 11 / 2018]$

51. Olsen, K. H. and Fenhann, J.V. (2016) Transformational Change Taxonomy, UNEP DTU Partnership, can be from: http://orbit.dtu.dk/files/126662425/TC Taxonomy_NAMA_Partnership web.pdf [accessed on $04 / 11 / 2018$ ]

52. Olsen, K. H. and Fenhann, J.V. (Eds.) (2015) Transformational Change for Low Carbon and Sustainable Development, Copenhagen: UNEP DTU Partnership, Perspectives Series, can be accessed from: http://orbit.dtu.dk/files/115264160/UNEP Transformational web.pdf [accessed on 04/11/2018]

53. Organisation for Economic Co-operation and Development (OECD) (2003) "Concessional loans", https://stats.oecd.org/glossary/detail.asp?ID=5901 [accessed on 04/11/2018]

54. Peters, T. (2018) Global Clean Cooling Landscape Review, University of Birmingham, UK

55. Petticrew, M. and Roberts, H. (2006) Systematic Reviews in the Social Sciences, Blackwell Publishing, Oxford, UK

56. Pieri, T.; Nikitas, A.; Castillo-Castillo, A. and Angelis-Dimakis, A. (2018) "Holistic Assessment of Carbon Capture and Utilization Value Chains", Environments, 5 (10)

57. Porter, M. and Kramer, M.R. (2011) "Creating Shared Value", Harvard Business Review, January-February 2011 issue

58. Pricewaterhouse Coopers Consultants (PWC) (2013) "Exploring green finance incentives in China", PWC

59. Saunders, M., Lewis, P. and Thornhill, A. (2007) Research Methods for Business Students, $4^{\text {th }}$ Edition, Harlow: Pearson Education Limited

60. Saunders, M., Lewis, P. and Thornhill, A. (2009) Research Methods for Business Students, $5^{\text {th }}$ Edition, Harlow: Pearson Education Limited

61. SEforAll (2018) "Chilling prospects: providing sustainable cooling for all", SEforAll and Kigali Cooling Efficiency Program, can be accessed from: https://www.seforall.org/sites/default/files/SEforALL_CoolingForAll-Report.pdf [accessed on $10 / 11 / 2018$ ]

62. Styring, P.; Jansen, D.; de Coninck, H.; Reith, H. and Armstrong, K. (2011) "Carbon capture and utilisation in the green economy: using $\mathrm{CO} 2$ to manufacture fuel, chemicals and materials", Centre for Low Carbon Futures 2050, can be accessed from: http://co2chem.co.uk/wpcontent/uploads/2012/06/CCU\%20in\%20the\%20green\%20economy\%20report.pdf [accessed on 10/11/2018]

63. Super-efficient Equipment and Appliance Deployment (SEAD) (2019) "About us", can be accessed from: https://superefficient.org/about-us/what-is-the-sead-initiative [accessed on $16 / 02 / 2019]$

64. Syed, A.M. (2017) "Environment, social, and governance (ESG) criteria and preference of managers", Cogent Business \& Management, 4, pp. 1-13

65. UK Government (2018a) Clean Energy Fund Technical Assistance Programme Annual Review 2018, Department for Business, Energy \& Industrial Strategy (BEIS), can be accessed from: https://aidstream.org/files/documents/CEF-TA-Programme-Annual-Review2018-20180820020824.pdf [accessed on 04/11/2018]

66. UK Government (2018b) International Carbon Capture, Usage and Storage (CCUS) Programme Annual Review 2018, Department for Business, Energy \& Industrial Strategy (BEIS), can be accessed from: https://aidstream.org/files/documents/CCUS-AnnualReview-2018-20180719120721.pdf [accessed on 04/11/2018] 
67. United Nations Framework Convention on Climate Change (UNFCCC) (2018) "Paris Agreement - Status of Ratification", can be accessed from: https://unfccc.int/process/theparis-agreement/status-of-ratification [accessed on 10/11/2018]

68. United Nations Framework Convention on Climate Change (UNFCCC) (2015) "The Paris Agreement", can be accessed from: https://unfccc.int/process-and-meetings/the-parisagreement/the-paris-agreement [accessed on 10/11/2018]

69. United Nations Framework Convention on Climate Change (UNFCCC) (2019) "Climate finance", can be accessed from: https:/unfccc.int/topics/climate-finance/the-bigpicture/climate-finance-in-the-negotiations [accessed on 16/02/2019]

70. United States Code (USC) (2018) 26 USC 45Q: Credit for carbon oxide sequestration, can be accessed from: http://uscode.house.gov/view.xhtml?req=(title:26\%20section:45Q\%20edition:prelim [accessed on 04/11/2018]

71. Warren, P. (2014a) "The use of systematic reviews to analyse demand-side management policy”. Energy Efficiency, 7, pp. 417-427

72. Warren, P. (2014b) "A review of demand-side management policy in the UK." Renewable and Sustainable Energy Reviews, 29, pp. 941-951

73. Warren, P. (2015) Demand-side management policy: mechanisms for success and failure, $\mathrm{PhD}$ thesis, University College London (UCL), UK

74. Warren, P. (2018a) "Evidence reviews in energy and climate policy" Evidence \& Policy

75. Warren, P. (2018b) "Demand-side policy: global evidence base and implementation patterns", Energy \& Environment, 29 (5), pp. 706-731

76. Warren, P. (2019) "Demand-side policy: mechanisms for success and failure", Economics of Energy and Environmental Policy

77. Warren, P. 2017. "Transferability of demand-side policies between countries." Energy Policy, 109, pp. 757-766

78. Westphal, M.I.; Canfin, P.; Ballesteros, A. and Morgan, J. (2015) "Getting to \$100 Billion: Climate Finance Scenarios and Projections to 2020", Working Paper, Washington, DC: World Resources Institute, can be accessed from: www.wri.org/publication/getting-to-100billion [accessed on 04/11/2018]

79. Winkler, H. and Dubash, N.K. (2016) "Who determines transformational change in development and climate finance?" Climate Policy, 16 (6), pp. 783-791

80. World Resources Institute (WRI) (2018) "COP 24 - Climate change package brings Paris Agreement life", can be accessed from: https://www.wri.org/blog/2018/12/cop24-climatechange-package-brings-paris-agreement-life [accessed on 16/02/2019]

81. Zadek and Flynn (2013) "South-originating green finance: exploring the potential", The Geneva International Finance Dialogues, UNEP FI, SDC and iisd

Search Sources

Web of Science

UNFCCC 


\begin{tabular}{|l|}
\hline World Bank \\
\hline ADB \\
\hline OECD \\
\hline IEA \\
\hline CPI \\
\hline IPCC \\
\hline UK Government \\
\hline GIZ Proklima \\
\hline
\end{tabular}

\begin{tabular}{|l|}
\hline Search Terms \\
\hline "sustainable cooling" OR "low carbon cooling" OR "clean \\
cooling" AND investment OR funding OR finance \\
\hline "carbon capture, usage and storage" or "carbon capture and \\
storage" AND investment OR funding OR finance
\end{tabular}

\begin{tabular}{|l|}
\hline Inclusion Criteria \\
\hline English language documents \\
\hline Documents freely accessible online and downloadable \\
\hline Snowballing reference lists \\
\hline No geographical or temporal exclusions \\
\hline
\end{tabular}

\begin{tabular}{|l|}
\hline Quality Assessment Scale \\
\hline $\begin{array}{l}\text { Clear and justified rationale (1 point) and research questions } \\
\text { (1 point) }\end{array}$ \\
\hline $\begin{array}{l}\text { Resource contributions acknowledged (1 point) and possible } \\
\text { conflicts of interest stated (1 point) }\end{array}$ \\
\hline $\begin{array}{l}\text { Peer reviewed by one reputable expert (1 point) or more than } \\
\text { one reputable expert (2 points) }\end{array}$ \\
\hline Methods are suitable for the aims of the study (1 point) \\
\hline Conclusions match the data presented (1 point) \\
\hline $\begin{array}{l}\text { Author(s) / publishing organisation(s) have a track record in } \\
\text { the area (1 point) }\end{array}$ \\
\hline
\end{tabular}

Table 1: the review protocol for the evidence reviews

Enabling Contextual Conditions

Supportive political environment

Appropriate policy, regulatory or legislative support 


\begin{tabular}{|l|}
\hline Innovation (technologies, processes or institutions) \\
\hline $\begin{array}{l}\text { Private sector support (financial or non-financial such as } \\
\text { expertise, land or people resources) }\end{array}$ \\
\hline $\begin{array}{l}\text { Public sector support (financial or non-financial such as } \\
\text { expertise, land or people resources) }\end{array}$ \\
\hline Replicability within countries \\
\hline Transferability between countries \\
\hline Local ownership \\
\hline
\end{tabular}

Table 2: key enabling contextual conditions to enable transformational change 


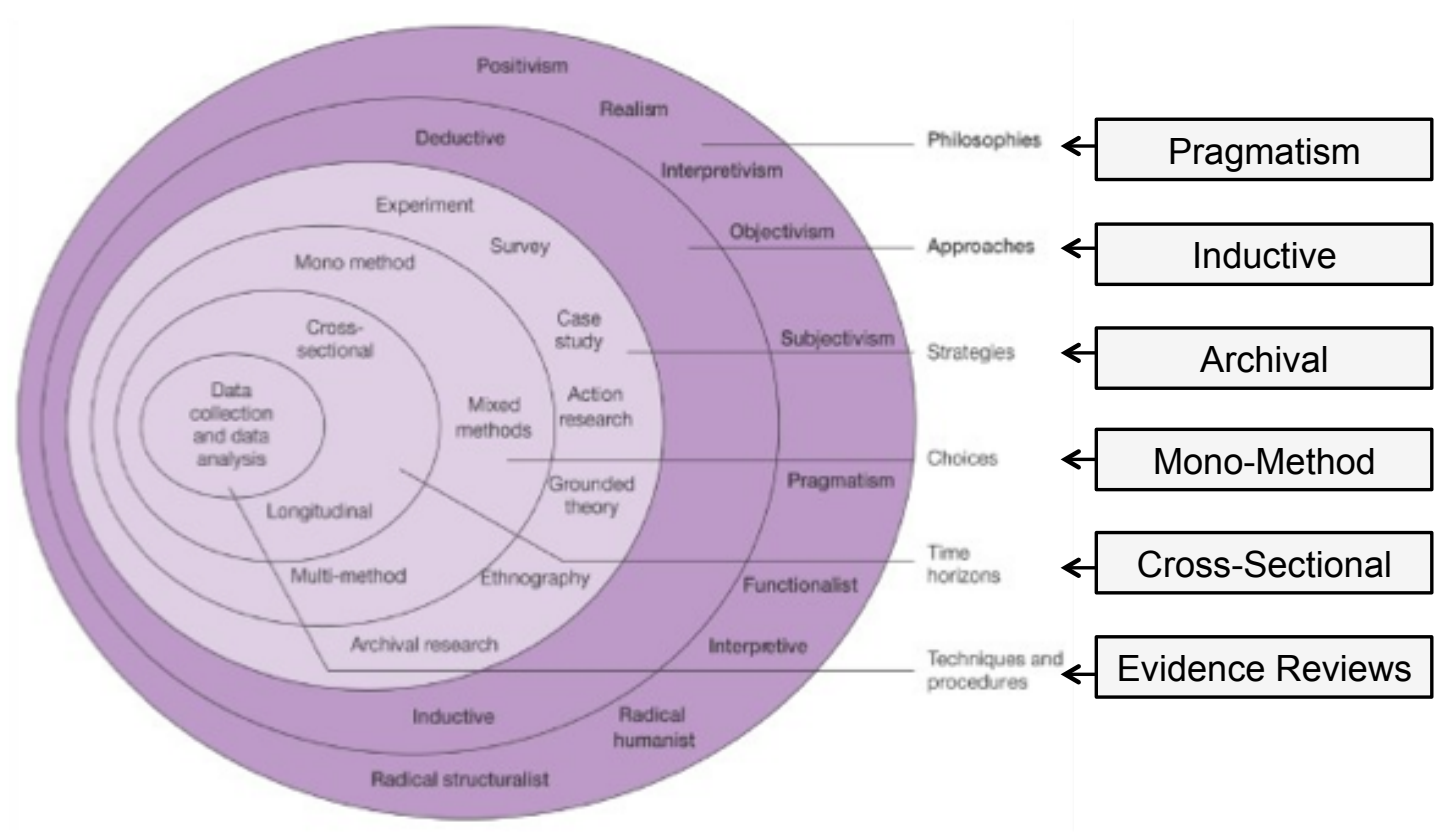

Figure 1: the research design for the synthesis 

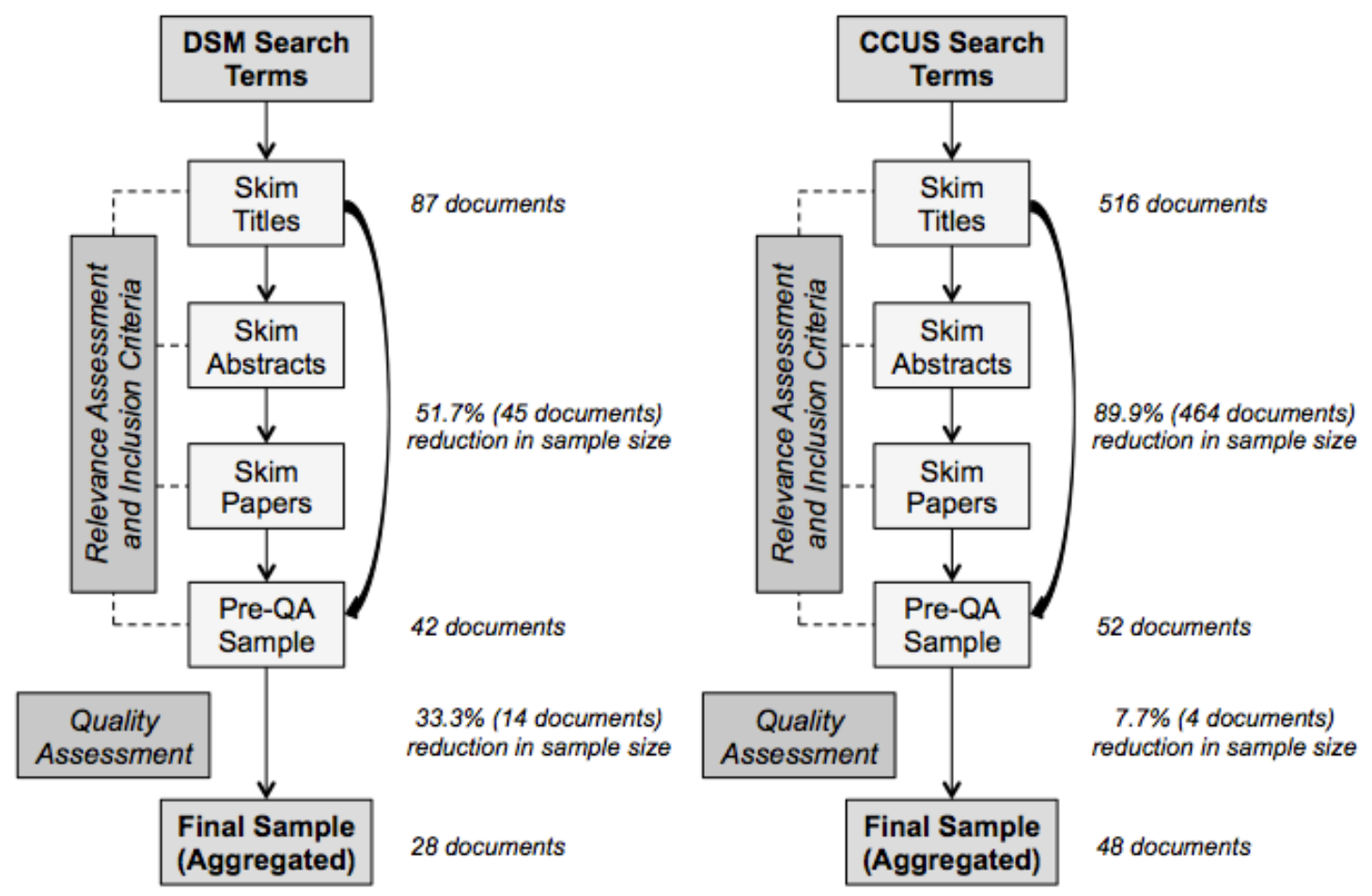

Figure 2: the filtering process to produce the final sample 


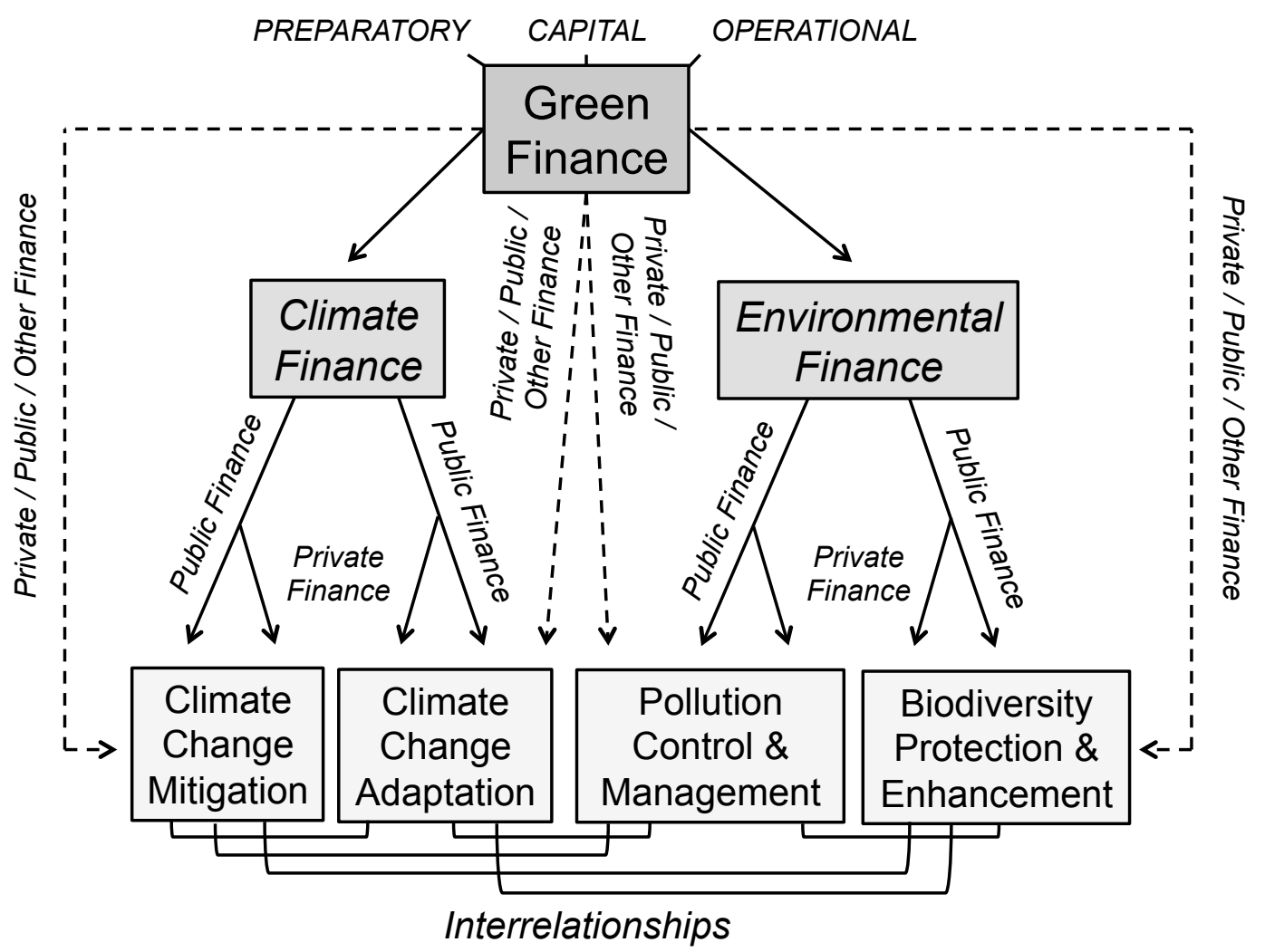

Figure 3: the interrelationships between key terms in climate finance 


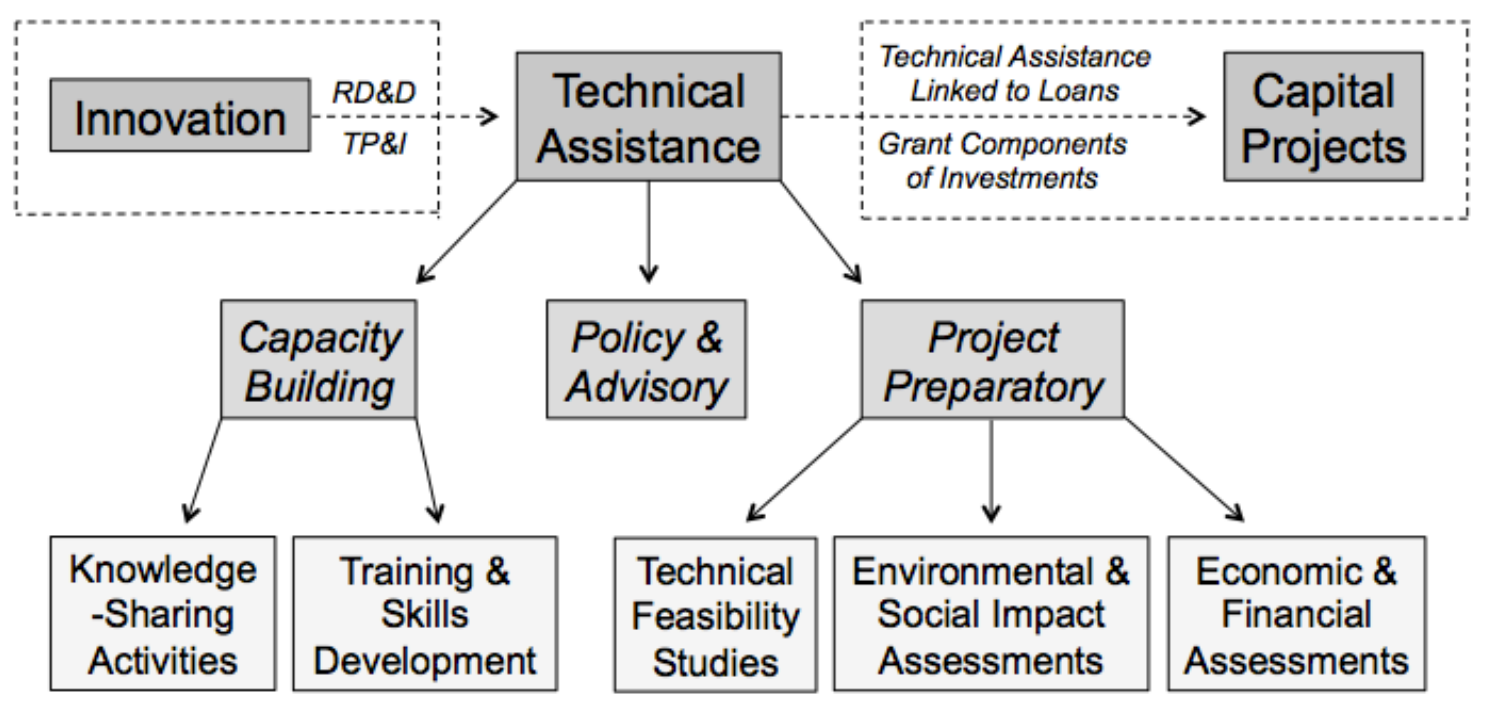

Figure 4: framework for defining technical assistance in climate finance 


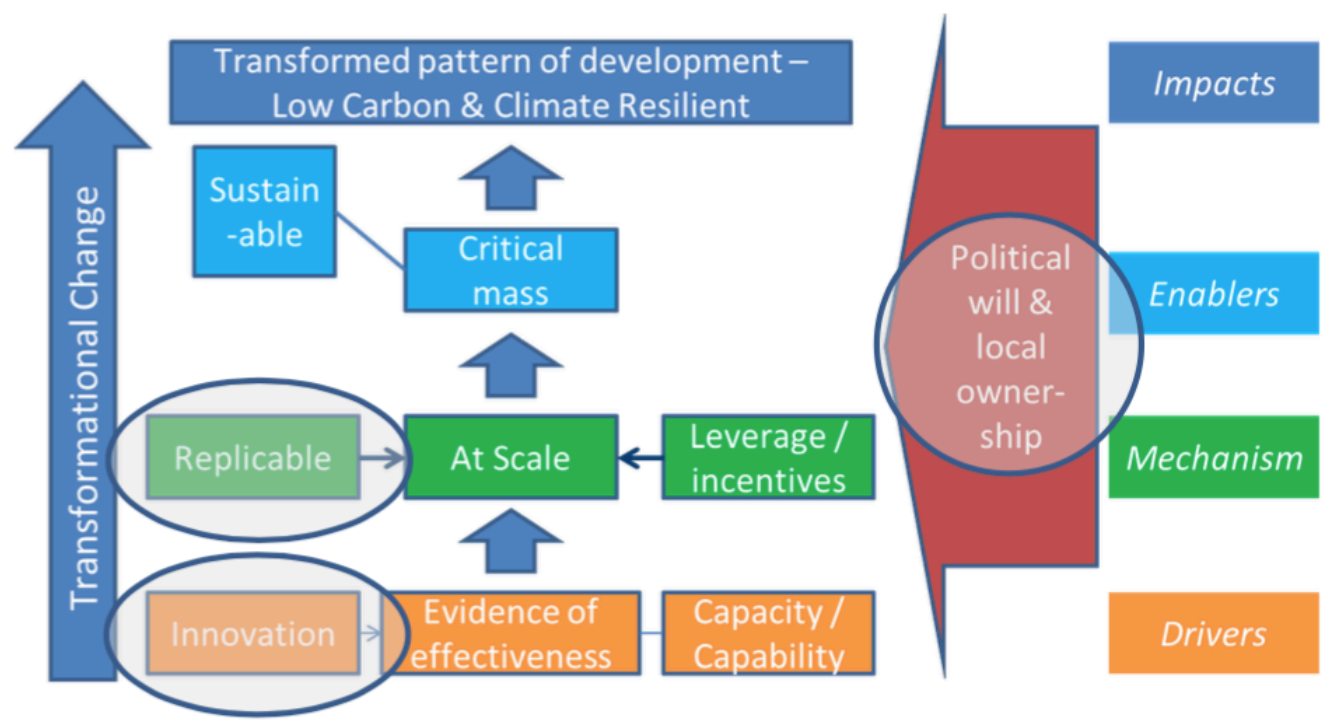

Figure 5: summary theory of change for transformational change in carbon capture, usage and storage (CCUS) (UK Government, 2018b) 